\title{
ZENDING EN IMPERIALISME IN ZUID-AFRIKA
}

\section{Dr. C. de Jong, Dept. Ekonomie, Unisa, Pretoria}

EVENALS het Westerse imperialisme en kolonialisme is na Wereldoorlog II de Christelijke zending onder schot genomen. Deze zending wordt door anti-Westerse en antikapitalistische stromingen als handlanger van Westers imperialisme beschouwd. Onder meer in Noorwegen hebben zendingsvrienden zich dat verwijt aangetrokken. Dit vroeger arme land is een der eerste en ijverigste zendingslanden in Europa. De Noorse zending heeft pionierswerk in Natal verricht en ik meen, dat haar betekenis in Zuid-Afrika eerder onder- dan overschat wordt, wegens gebrek aan kennis van de Skandinavische talen en bronnen.

Sinds 1970 hebben verscheidene Noorse theologen en historici, met name Lislerud, Hakkevig, Simensen en Myklebust (laasgenoemde eertijds zendeling in Zuid-Afrika) artikelen over het vraagstuk zending en imperialisme gepubliceerd. ${ }^{1} \mathrm{Zij}$ kunnen niet ontkennen, dat vó́r Wereldoorlog I Christelijke zendelingen dikwijls politieke uitbreiding door Europese mogendheden overzee hebben gesteund en dat Westerse imperialisten de zending als zeer bruikbare hulp voor kolonisatie beschouwen. Hakkevig uit de scherpste kritiek op de zendelingen en hun blank meerderwaardigheidsgevoel. Lislerud en Myklebust trachten het optreden der zendelingen te vergoeilijken door te wijzen op hun onvermijdelijke gebondenheid aan Westerse denkbeelden en cultuur, op positieve bijdragen van de zending aan schoolopleiding, beëindigen van slavenhandel, van heksenvervolging, van stamoorlogen en andere vermeende misstanden in blanke ogen en op overdrijving van de kritiek, dat de zending heeft getracht inheemse cultuur te vernietigen.

Al deze schrijvers betogen, dat thans de zending opdringen van Westerse cultuur - m.a.w. cultuurimperialisme en demonstratie van blanke superioriteit - moet vermijden en inheemse cultuur moet eerbiedigen. Ik merk hierbij op, dat reeds de bekritiseerde zendelingen in de $19 \mathrm{e}$ eeuw dit hebben bepleit. Hoe de zendeling of missionaris moet optreden jegens polygamie, toverpraktijken en kinderhuwelijken als essentiële bestanddelen van andere culturen, daarover laten genoemde schrijvers zich niet uit.

Een belangwekkende bijdrage tot de discussie in Noorwegen is geleverd door Endre Eönstabö in zijn magistersverhandeling of doctorale scriptie voor het departement geschiedenis der universiteit te Trondheim in de lente van 1973. Zij telt 110 bladzijden en is getiteld Eortropper for europeisk imperialisme, Norske misjonaerer $i$ Zululand 1850-1880. Voorzover ik weet, is deze verhandeling niet gepubliceerd. Het grootste deel hiervan is een intelligente, objectieve beschrijving van de Zoeloesamenleving in de $19 \mathrm{e}$ eeuw en de uitwerking der Europese - speciaal Noorse - zending daarop. Hij heeft goed gebruik van gedrukte bronnen in het Noors, Engels en Duits gemaakt.

Zijn eerste vraag is, of de Noorse zendelingen zich identificeerden met de blanke kolonisten in Zuid-Afrika en de macht der blanke regering in Natal gebruikten voor hun zendingsdoel. Zijn antwoord 
is een stellig ja. Ik merk hierbij op, dat de Noorse zendelingen meestal partij kozen voor de Zoeloes en tegen de blanke kolonisten - zowel Boeren als Engelstaligen - waar het stoffelijke belangen gold. Zijn tweede vraag is, of men de Christelijke zending kan scheiden van het invoeren der Westerse beschaving. Hij antwoordt: Neen. Hij verklaart, dat de zending de redding van de ziel van de enkeling nastreeft en daardoor botste met de Zoeloesamenleving. Deze maakte de enkeling ondergeschikt aan de sibbe (groot familieverband) en de stam en huldigde voorouder- en vorstenverering als saambindend element in de sibbe en de stam, - evenals in de Oudgermaanse samenleving in Noorwegen en elders, waarnaar Sönstabö niet verwijst. De zending had een ontbindende uitwerking op de aan traditie en hiërarchie gebonden Zoeloesamenleving.

In de eerste hoofdstukken schetst de schrijver de geschiedenis en organisatie van de Zoeloestaat, welke elders reeds beschreven is. Deze was een bijna gesloten volkshuishouding met gering en marginaal handelsverkeer met blanken en zonder interne markten. De vorst en zijn hoofdmannen (indoena's) inden schatting in de vorm van vee, graan en arbeid van de onderdanen en deelden vee en graan uit, wanneer zi; dat goed oordeelden. Vermogensvorming was slechts mogelijk door vermeerdering van veebezit en van het aantal bijvrouwen. Polygamie was daarom een onmisbare instelling. Wanneer echter een gewone Zoeloe vermogend werd door bijzondere vlijt of kunde, liep hij spoedig groot gevaar, door toverdokters of medicijnmannen in opdracht van een aanzienlijke te worden aangeklaagd en „uitgesnuffeld", d.w.z. beschuldigd van ontoelaatbare toverpraktijken. Hij werd dan wreedaardig gedood of moest vluchten, en zijn bezit verviel aan de vorst. Aldus werd de sociale hiërarchie geconserveerd.

Naast voorouderverering was religieuze bevordering der vruchtbaarheid belangrijk door drink- en danspartijen, saturnaliën en sexuele orgicën, waarover de Noorse zendelingen met Victoriaanse preutsheid zelden uitweiden, doch waartegen zij zich sterk kantten. Zij boden de Zoeloes een "zendingspakket" (,pakkelösning” noemt Sostabo dit), bestaande uit redding van de ziel, schoolopleiding (eerst na 1880), geregelde loonarbeid op een zendingsstation, Europese gereedschappen en gebruiksartikelen en de mogelijkheid om door arbeid en handel rijkdom te vergaren. Voor de meeste Zoeloes was dit pakket weinig aantrekkelijk, want kerstening betekende uittreden uit de sibbe en de stam en tot 1879 verbood de vorst bekering op straffe des doods. Want de Zoeloe-elite begreep heel goed, dat bekering betekende afvalligheid van de vorst en dienstweigering wegens de ontoelaatbaarheid voor Zoeloe-Christenen van polygamie en vervulling van militaire dienst met zijn dansen en heidense ceremoniën.

Voordat in 1879 de militaire kracht der Zoeloes door de Engelsen werd gebroken, vestigden slechts bedreigde Zoeloes zich op de zendingsstations en lieten zich dopen. Dat waren meisjes die niet wilden trouwen met een veel oudere man, die eerst na lange militaire dienst van de vorst verlof kreeg om te trouwen, jongemannen die de krijgsdienst en het huwelijksverbod wilden ontgaan, 
familieleden van Zoeloes die van tovenarij waren aangeklaagd en mannen die rijkdom wilden vergaren door handel.

Sonstabo verklaart, hoe na de verdrijving der eerste zendelingen uit Zoeloeland de Noor Hans P. Schreuder (1817-82) van Mpande verlof kreeg om als eerste weer een zendingspost te openen en later meerdere op te richten. Schreuder verkreeg ook toegang voor de Duitse Lutherse zending. Hij bezat grote diplomatieke gaven en trad meermalen op als bemiddelaar tussen de Natalse en de Zoeloeregering, zodat hij groot aanzien verwierf. Veelzeggend is, dat Cetswayo, Mpandes zoon en opvolger in 1873-79, aan Schreuder de grond van het zendingsstation Entumeni als particulier eigendom schonk en aldus het Zoeloerecht, dat slects collectieve grondeigendom van het Zoeloevolk kende, doorbrak. Toen de oorlog met Brittannië in 1879 uitbrak, stuurde Cetswayo soldaten om Entumeni en de Christenen aldaar tegen zijn volk te beschermen. Entumeni was daardoor het enige zendingsstation dat in 1879 niet is verwoest.

Wegens het verbod tot bekering doopten de Noorse zendelingen in 1850-80 slechts 300 Zoeloes, waarvan velen naar Natal moesten vluchten. Ze onderhielden redelijk goede betrekkingen met Mpande en Cetswayo als kroonprins, want dezen vonden de zendelingen bruikbaar als arts, diplomatiek onderhandelaar met de Britten en brenger van Europese artikelen. Zij wilden ook de Britse regering als beschermer der zendelingen en als tegenwicht tegen de druk der Transvalers op hun noordgrens te vriend houden.

Maar na de troonsbestijging van Cetswayo in 1873 werd zijn houding zeer onvriendelijk, want hij vreesde de toenemende invloed der zending. Kort na zijn inhuldiging verbande hij alle zendelingen. Slechts de tussenkomst van Schreuder als de meest gerespekteerde zendeling, die een beroep op de Natalse regering deed, voorkwam hun verdrijving uit Zoeloeland. Sönstabö beklemtoont, dat dit de eerste maal was, dat de Noorse en andere zendelingen openlijke inmenging der Britse regering vroegen. In 1877 begin een ware Christenvervolging met martelaren. Sönstabô verklaart deze uit reactie tegen de verzwaarde Britse druk op Zoeloeland; in dat jaar annexeerde de Britse regering Transvaal en zij trad daar op als verdediger van Transvaalse aanspraken op Zoeloeland.

De Hoge Commissaris Frere en de Natalse secretaris voor Naturellenzaken Shepstone besloten in 1877 om de bedreiging door het krijgshaftige Zoeloevolk te beëindigen door zijn macht te breken. Sönstabö beklemtoont, dat de Zoeloes zich steeds zorgvuldig voor grensoverschrijding hoedden, dat bewijst voor een dreigende Zoeloe-inval in Natal en Transvaal ontbreekt en dat Cetswayo na het Britse ultimatum aan hem gericht een beroep op Schreuder deed als bemiddelaar op te treden. In navolging van de Natalse Zoeloevriend bisschop Colenso, meent Sönstabö, dat de Britse regering een voorwendsel voor verowering van Zoeloeland zocht. Frere wees Cetswayo's verzoek om onderhandeling via Schreuder met verachting af. Hij berichtte naar Londen: „Cetswayo's arrogance has increased ... a final settlement is now inevitable". Een soortgelijk optreden door de Britse Hoge Commissaris Milner viel Transvaal in 1875 en weer in 1899 te beurt. 
Volgens Sönstabö was Schreuder jegens Cetswayo illoyaal ondanks Cetswayo's vertrouwen in hem. Schreuder kreeg inlichting van Christen-Zoeloes te Entumeni over grote troepenconcentratie en hij gaf deze inlichting dadelijk door aan de Britse autoriteiten op 20 januari 1879. Hij kon echter de Britse nederlaag te Isandlhwane op 22 januari niet voorkomen. Sönstabö meent, dat de Zoeloevorst gelijk had, toen deze zei, dat Christen-Zoeloes de partij van de blanken en niet van hem zouden kiezen.

Het breken van de militaire macht der Zoeloes in 1879 had het door de Zendelingen gewenste effect: nadat het vorstelijk verbod van bekering was vervallen steeg het aantal Zoeloedopelingen snel.

Veelzeggend is de slotzin van de hier besproken verhandeling: Indien men zijn aandacht concentreert op de boodschap der zendelingen, is het moeilijk te begrijpen, hoe deze boodschap kan worden gescheiden van de ,spirit of capitalism' en dus van een klassestructuur, welke de zaak van het imperialisme dient. Hij beschouwt dus het Westerse kapitalisme als de voornaamste drijfveer van het neo-imperialisme in 1880-1920 - hetgeen ik ontken - en de „missionary factor" als dienaar van dit imperialisme. Aldus schaart hij zich bij de linkse critici van kapitalisme en zending.

Het is waar, dat men geen mensen kan kerstenen en tevens hun niet-westerse samenleving, gekenmerkt door collectivisme, voorouderverering, veelwijverij en tovenarij, in stand kan laten.

Afgezien van Sönstabö's aangehaalde slotzin is zijn geschrift interessant en verdient het een vertaling in het Engels.

1 G. Lislerud, „Er misjon kulturimperialisme?" in Tidskrift for teologi og kirke, heîte 3, 171, p. 195-206.

Trond Bakkevig, „Er misjon kulturimperialism?” in Kirke og kultur, maart 1972, xxx, 5 pp.

Olav Guttorm Myklebust, „Misjonen og imperialismen”, in Syn og segn, 1975 , p. $36-45$.

J. Simensen, Afrika, Oslo 1970; hij heeft in de lente van 1976 in de Zendingsschool te Stavanger een voordracht over zending en imperialisme gehouden.

\section{TYDSKRIFOORSIG}

Teen die agtergrond van 'n soort konsensus van Ou-Testamentici dat die rykdom van die $\mathrm{Ou}$ Testament onmoontlik onder een tema behandel kan word, verskyn twee interessante artikels van SuidAfrikaanse teoloë oor hierdie onderwerp. ${ }^{1}$

\section{Helberg oor die koninkryk van God en OT}

Prof. Helberg gee 'n weergawe in Engels van die lesing wat hy reeds in 1975 by die aktualiteitskursus van die Teologiese Skool te Potchefstroom behandel, en waarin hy aantoon dat met 'n (openbarings-) historiese benadering van die Ou Testament dit tóg vrugbaar is om as uitgangspunt die koninkryk van God te neem. Die koninkryk van God is die absolute heerskappy van die soewereine, lewende God in en deur die geskiedenis, deur sy Woord, in persoonlike verbonds- 
gemeenskap met die mens, alhoewel die mens ten dode gevalle is. Dit is duidelik hoedat die verbondsgedagte in hierdie benadering tot sy reg kom. Die profesie kom tot sy reg (heerskappy deur die Woord); en eweneens die poëtiese gedeeltes, as antwoord van die mens in hierdie verbondsgemeenskap.

Ek wil nie verder hierop uitbrei nie, en volstaan met die opmerking dat een van die dinge wat my in hierdie benadering aangryp dít is dat die spanning tussen heilshistoriese en heilsordelike prediking opgelos word en elkeen sy regte aksent ontvang in die persoonlike aanspraak van die Ou Testament op elkeen wat dit hoor. Verder wil ek net verwys na die interessante kommentaar in die bulletin deur vyf Ou-Testamentici by wyse van diskussie.

\section{Woudstra oor Helberg se siening}

Die interessantste is die van prof. $M$. H. Woudstra van die Calvin Theological Seminary. Hy skryf: „Prof. Helberg's article abounds in valuable insights", hoewel hyself 'n bietjie huiwerig bly om die Ou Testament onder een motief te probeer behandel. Nogtans waardeer hy die benadering. Sy vernaamste twee punte van kritiek is, eerstens: Hy vind dit pragtig dat prof. Helberg die Ou Testament benader vanuit Jesus se antwoord aan die Sadduseërs oor die woorde van die HERE aan Moses: „Ek is die God van Abraham ens.”, en God is die God van die lewendes, wat beteken dat Abraham leef - gemeenskap met die lewende God beteken ewige lewe. Maar hy voel dat, vanuit die agtergrond van Moses self gesien (lewe is lewe in die liggaam), Helberg die implikasies vir die opstanding duideliker moes deurgetrek het.

Tweedens: Die historiese benadering bring tog sy probleme mee as nie voldoende rekening gehou word met die afsonderlike aksente van die openbaring in verskillende boeke wat die openbaringsgeskiedenis weergee, soos bv. in die profetiese geskiedskrywing van Samuel/Konings aan die een kant en Kronieke wat dieselfde tydperke behandel, aan die anderkant nie.

Interessant is ook die repliek van Helberg op die kommentaar van Sierd Woudstra van die Reformed Church in Hobart, Tasmanië. Laasgenoemde maak die bewering: „Israel's history . . . is basically a history of the failure of the old covenant". Helberg se antwoord hierop is tereg (vgl. Rom. $7: 12$ ): „I do not think that we can speak of a failure of the old covenant - just as we cannot speak of a failure of the law. Calvin saw this in better perspective than did Luther. The failure is not something impersonal and does not lie in an institution or structure, but it is primarily something personal. It is the people who failed, not the covenant".

\section{Verhoef oor die brug tussen OT en prediking}

Prof. Verhoef se artikel oor Die weg en die brug tussen Ou-Testamentiese teks en prediking raak dieselfde veld. Hy begin met die opmerking dat die vroeëre dichotomiese benadering van 'n preek in terme van explicatio en applicatio nie meer bevredig nie. Die 
verband tussen eksegese en preek is veel nouer en wesenliker. Albei is uitleg van die teks.

By die bespreking van "die weg" is Verhoef se uitgangspunt dat 'n teks destyds 'n bepaalde boodskap oorgedra het en dat daardie boodskap op een of ander manier met die groot temas van die Skrif verband hou. Hy gebruik dan die beeld van 'n snelweg met verskillende bane wat parallel aan mekaar loop, „wat die proprium van die teks oor die brug heen na sy bestemming in die prediking laat beweeg". Hierdie „bane” is dan: die koningsheerskappy van God, waardeur alle dinge in die weg van oordeel en heil na hulle eindbestemming gevoer word; die verkiesing en verbond van God met Israel; die Messiaanse verwagting; die wetgewing as koninkryksadministrasie, en as aanduiding van die lewe in die verbond; die erediens, met sy tempel en offers en priesterskap, waarin die skadu van die toekomstige werklikheid op Israel se pad geval het; en ten slotte die eskatologiese perspektief op die voleinding.

Ons kan nie sinvol oor 'n Ou-Testamentiese teks preek as ons die nie met een of meer van hierdie „bane" in verband gebring het nie. Die bane vorm die wydste verband waarin die teks verklaar moet word. Anders sou die prediker sy toevlug tot allegorisering, moralisering of eksemplariese prediking moes neem. Dan word Jakob, Dawid of die profeet uit hulle heilshistoriese konteks gehaal en vervlugting tot eksemplare van ,die mens”. „Wég is die verbondsamehang, wég is die betekenis van hierdie manne as draers van die heilsbeloftes van God, wég is hulle unieke posisie as skakels in die ketting wat die belofte aan die vervulling verbind".

Hoe preek die prediker nou vir 'n Nieu-Testamentiese gemeente oor 'n Ou-Testamentiese teks? Die geheim lê by „die brug". Hierdie brug is Christus. Om trinitaries te preek, beteken om christologies te preek: ,Ek is die weg, die waarheid en die lewe; niemand kom na die Vader behalwe deur My nie" (Joh. $14: 6$ ). By hierdie brug ontvang die Ou-Testamentiese teksmateriaal sy diepste sin, of dit vervlugtig tot allegorie en moralisme. Ons mag dus sê dat die prediking daarby staan of val om ongeskonde oor hierdie brug te kom.

Die leser kan vir homself besef dat die baan van die koningsheerskappy van God lynreg deur Christus oor hierdie brug vloei. Hier is daar meer kontinuïteit as diskontinuiteit. Wat betref die baan van die verkiesing en verbond, kom daar die verandering dat dit nou na die volkere uitgebrei word. Die baan van die Messiaanse verwagting stuur in al sy verskeidenheid reg op die brug af. Die baan van die wetgewing as koninkryksadministrasie stuur ook op Christus af en word deur Hom in die Bergrede en elders geïnterpreteer. Daar kom veral dié nuwe element by dat $\mathrm{Hy}$ in ons plek aan die eise van die Wet voldoen het, en ons vrygemaak het om die Wet te kan volbring, deur die heerskappy van sy Heilige Gees oor ons (Rom. $8: 4$ ).

Wat betref die baan van die erediens, waar die heilige God 'n sondige volk ontmoet: waar vind ons hierdie gemeenskap anders as in Christus na wie die erediens van die Ou Testament heenwys? Die laaste baan, dié van die eskatologiese verwagting, word voort- 
gesit deur die Nieu-Testamentiese materiaal van dieselfde aard, belig deur die vervulling in Christus, en vestig ons blik op die skare wat niemand kan tel nie, uit alle volke, en 'n nuwe aarde waarop geregtigheid woon.

\section{A. D. Pont oor Skrif en Kerkorde}

Een kort aanhaling uit die pen van die Hervormde teoloog, prof. A. D. Pont, wat seker ons instemming verdien. ${ }^{2}$ Dit gaan oor die samehang van Skrif en kerkorde: „(die) organisatoriese samehang van Skrif, belydenis en Kerkorde is van fondamentele waarde vir die kerk en as dit verstar word, soos bv. in Nederland waar die owerheid in 1816 sy eie kerkorde op die kerk afgedwing het sonder inagneming van (die Skrif? - J.A.v.R.) of die belydenis, dan is die kerk en alles wat kerk is en wil wees die lydende party. Juis in die geskiedenis van die Nederlandse Hervormde Kerk en sy innerlike worstelstryd vanaf 1816 met ál die ellende wat daaruit voortgevloei het, word duidelik dat die kerklike reg en orde sui generis is en dat dit nie straffeloos vervang kan word met die denke of opvattings wat nie beheers word deur die waarheid van die Skrif as ' $n$ geheel en die geloof wat uit die belydenisskrifte spreek nie. Dit blyk dan ook verder ten oorvloede dat baie van die ,geleentheidswetgewing', wat veels te dikwels in ons kerke voorkom, op die lang duur meer skade as goed doen, en hoewel dit op die kort termyn wel allerlei voordele mag bring, is en was dit nog nooit tot die werklike opbouing van die liggaam van Christus nie".

\section{F. H. Klooster oor Pannenberg}

Ten slotte 'n kort opsomming van 'n artikel van prof. Fred Klooster van die Calvin Seminary oor die teologie van Wolfhart Pannenberg, 'n hedendaagse Duitse teoloog wat die historiese feitlikheid van die Nieu-Testamentiese heilsfeite as essensiële element van die evangelie en van ons geloof wil handhaaf teenoor wat Klooster noem "the historically docetic theologies of Rudolf Bultmann and Karl Barth" - wat elkeen op sy eie manier die boodskap van die Woord skei van sy historiese openbaring. Hierteenoor betoog Pannenberg tereg dat die kerugma gewortel moet wees in die historiese Jesus en sy geskiedenis, want die kerugma gee slegs die betekenis weer van die gebeurtenisse. „All meaning has its criterion in the fact in which it inheres".

Terselfdertyd bestry Pannenberg die positivistiese benadering van Ernst Troeltsch van die godsdienshistoriese skool, wat enigiets wat ,'n daad van God" genoem kan word, by voorbaat wil uitsluit uit sy historiese navorsing oor Jesus Christus.

Pannenberg beskou Barth se benadering as 'n vlug in 'n hawe in die waan dat dit veilig is teen die krities-historiese vloedgety, die hawe van 'n supra-historie. Van Bultmann sê hy dat hy ,hom onttrek het aan die sinlose en goddelose verloop van die ,objektiewe' geskiedenis na die ervaring van die betekenis van die geskiedenis in die ,Geschichtlichkeit' van die enkeling". 
Panncnberg beskou teologie as „die wetenskap oor God". Omdat hy besef dat God nie in ons fenomenologiese ervaring voorkom nie, wil hy die oplossing soek in wat hy noem die ,indirekte aard van die openbaring". Die werklikheid van God is nl. gegee met ander objekte van ons ervaring, sodat die teologiese besinning oor God indirek eerder as direk geskied.

Hy het heelwat ter sake opmerkings oor die aanspraak van kritiese teoloë dat hulle objektiewe geskiednavorsing beoefen. Geen historikus, sê Pannenberg, kan historiese ondersoek aanpak sonder enige voorveronderstellings nie. Om by voorbaat die moontlikheid van transsendente werklikheid uit te sluit - wat as die toppunt van wetenskaplikheid moet geld - is 'n vooroordeel en 'n onwetenskaplike een daarby, wat die voortgang van historiese navorsing belemmer. „The possibility of the historicity of Jesus' resurrection has been opposed on the grounds that the resurrection of a dead person even in the sense of the resurrection of imperishable life would be an event that violates the laws of nature". Hierdie benadering moet egter in die lig van die moderne fisika met versigtigheid geskied. Eerstens is slegs 'n deel van die wette van die natuur ooit bekend. Tweedens is by ' $n$ gebeurtenis nie net natuurwette nie, maar ook menslike en goddelike handeling betrokke. Dit bring iets van 'n uniekheid in elke historiese gebeurtenis, wat die wette van analogie, waarop Troeltsch so sterk staan, trotseer. 'n Historikus mag dus nie die feite opsyskuif as dit vir hom ,onmoontlik" lyk nie.

By wyse van kritiek op Pannenberg se benadering skryf Klooster: Pannenberg maak daarop aanspraak dat hy 'n skriftuurlike siening op die teologie en die geskiedenis het, maar terselfdertyd verwerp hy die Skrif se aanspraak op gesag. Terwyl hy 1 Kor. 15 as histories betroubaar erken, beweer hy sonder meer dat die weergawes van die opstanding in die Evangelies legendariese elemente bevat.

Hy orken dat die lewende God homself werklik in die geskiedenis openbaar, maar wil terselfdertyd die „oop rasionalisme van die Verligting" aanvaar. "If it is really the revelation of God to which one appeals", sê Klooster, „what is so bad about an appeal to authority?"

J. A. van Rooy.

1 Helberg, J. L.: A startingpoint and method for Old Testament study: Meaning for the New Testament and for the life of the church. R.E.S. Theological Bulletin, Vol. IV, No. 2. Verhoef, P. A.: Die weg en brug tussen Ou-Testamentiese teks en prediking. N.G. Teologiese Tydskrif. Dl. XVIII, Nr. 2, pp. 145-157.

2 Pont, A. D.: Skrif en Kerkorde - enkele opmerkings. Hervormde Teologiese Studies, Jaargang 33, Afl. 1 en 2, p. 89.

3. Klooster, Fred H.: Historical method and the resurrection in Pannenberg's theology. Calvin Theological Journal, Vol. II, No. 1, pp. 5-33. 